\title{
Design and statistical optimization of glipizide loaded lipospheres using response surface methodology
}

\author{
HAGALAVADI NANJAPPA SHIVAKUMAR ${ }^{1 *}$ \\ PRAGNESH BHARAT PATEL ${ }^{1}$ \\ BAPUSAHEB GANGADHAR DESAI ${ }^{1}$ \\ PURNIMA ASHOK ${ }^{2}$ \\ SINNATHAMBI ARULMOZHI ${ }^{2}$ \\ ${ }^{1}$ Department of Pharmaceutical and \\ 2 Department of Pharmacology \\ K.L.E.S's College of Pharmacy \\ Bangalore-560010, India
}

\begin{abstract}
A $3^{2}$ factorial design was employed to produce glipizide lipospheres by the emulsification phase separation technique using paraffin wax and stearic acid as retardants. The effect of critical formulation variables, namely levels of paraffin wax $\left(X_{1}\right)$ and proportion of stearic acid in the wax $\left(\mathrm{X}_{2}\right)$ on geometric mean diameter $\left(d_{\mathrm{g}}\right)$, percent encapsulation efficiency $(\% E E)$, release at the end of $12 \mathrm{~h}\left(\mathrm{rel}_{12}\right)$ and time taken for $50 \%$ of drug release $\left(t_{50}\right)$, were evaluated using the F-test. Mathematical models containing only the significant terms were generated for each response parameter using the multiple linear regression analysis (MLRA) and analysis of variance (ANOVA). Both formulation variables studied exerted a significant influence $(p<0.05)$ on the response parameters. Numerical optimization using the desirability approach was employed to develop an optimized formulation by setting constraints on the dependent and independent variables. The experimental values of $d_{\mathrm{g}}, \% E E$, rel $_{12}$ and $t_{50}$ values for the optimized formulation were found to be $57.54 \pm 1.38 \mu \mathrm{m}, 86.28 \pm 1.32 \%$, $77.23 \pm 2.78 \%$ and $5.60 \pm 0.32 \mathrm{~h}$, respectively, which were in close agreement with those predicted by the mathematical models. The drug release from lipospheres followed first-order kinetics and was characterized by the Higuchi diffusion model. The optimized liposphere formulation developed was found to produce sustained anti-diabetic activity following oral administration in rats.
\end{abstract}

Keywords: lipospheres, glipizide, factorial design, response surface methodology, optimization

Oral multiparticulate systems show several advantages in comparison with single unit dosage forms, such as more predictable gastric emptying, gastric emptying less dependent on the state of nutrition, high degree of dispersion in the digestive tract, lesser risk of dose dumping and reduced local irritation (1).

\footnotetext{
* Correspondence, e-mail: shivakumarhn@yahoo.co.in
} 
Though a number of microencapsulation techniques have been employed to produce peroral polymeric multiparticulate systems (2), the toxicity of the residual organic solvent in the final product and the use of potentially toxic monomers are the major concerns with these conventional microencapsulation techniques (3). In order to overcome these problems, the melt dispersion method has been proposed as a simple and useful technique to produce lipospheres without using any harmful organic solvents (4).

Glipizide is an oral hypoglycemic agent, which is a commonly prescribed drug for the treatment of patients with type II diabetes mellitus (5). It is a weak acid ( $\left.\mathrm{p} K_{\mathrm{a}}=5.9\right)$ practically insoluble in water and acidic environment but highly permeable (class 2 ) according to the Biopharmaceutical Classification System (BCS) (6). The oral absorption is uniform, rapid and complete with a bioavailability of nearly $100 \%$ and an elimination half-life of 2-4 h (6). Glipizide is reported to have a short biological half-life (3.4 $\pm 0.7 \mathrm{~h})$ requiring it to be administered in 2 to 3 doses of 2.5 to $10 \mathrm{mg}$ per day (7). Though a number of multiparticulate systems have been proposed for peroral controlled delivery of glipizide, most of them were polymeric drug delivery systems produced by conventional microencapsulation techniques $(8,9)$.

Use of the response surface methodology has been proved to be a useful tool in the development and optimization of controlled release microspheres (8). Different steps involved in response surface methodology include experimental design, regression analysis, constraint optimization and validation.

The current research was aimed at developing controlled release glipizide lipospheres employing the melt dispersion method since no such methods to produce glipizide lipospheres have been reported earlier.

\section{EXPERIMENTAL}

\section{Materials}

Glipizide was a generous gift sample from M/s Micro Labs (India). Paraffin wax was procured from Glaxo Laboratories Ltd. (India). Stearic acid, Tween 80, potassium dihydrogen orthophosphate, disodium hydrogen orthophosphate and sodium hydroxide were purchased from S.D. Fine Chemicals Ltd. (India). All the other regents and chemicals used were of analytical grade.

\section{Experimental design}

A 2 factor 3 levels full factorial design was employed to design controlled release lipospheres of glipizide (10). This design was suitable for exploring quadratic response surfaces and constructing second-order polynomial models. The two independent formulation variables analyzed during the study were the percentage wax loads in the liposphere formulation $\left(X_{1}\right)$ and the proportion of stearic acid in the wax $\left(X_{2}\right)$. The dependent variables investigated were the geometric mean diameter $\left(Y_{1}\right)$, encapsulation efficiency $\left(\mathrm{Y}_{2}\right)$, drug release at the end of 12 hours $\left(\mathrm{Y}_{3}\right)$ and the time taken for $50 \%$ of the drug to be released $\left(\mathrm{Y}_{4}\right)$. 
H. N. Shivakumar et al.: Design and statistical optimization of glipizide loaded lipospheres using response surface methodology, Acta Pharm. 57 (2007) 269-285.

\section{Preparation of drug loaded lipospheres}

Glipizide lipospheres were prepared employing a modified hydrophobic congealable dispersed phase encapsulation procedure (4). The mixture of paraffin wax and stearic acid was melted to obtain a one-phase melt on a thermostated hot plate (2 MLH, Remi Equipments Ltd., India). Glipizide was dispersed in the molten wax and the temperature of the resulting oily phase was maintained at $70{ }^{\circ} \mathrm{C}$. The surfactant solution comprising $1 \%(V / V)$ of Tween 80 in water was maintained at a temperature of $80^{\circ} \mathrm{C}$ under continuous stirring using a propeller stirrer (RQ $121 \mathrm{D}$, Remi Equipments Ltd.). The molten oily phase was emulsified in the aqueous surfactant solution maintained at 900 $\mathrm{rpm}$. Hardening of the oily internal phase resulting in encapsulation of the drug was accomplished by pouring twice the emulsion volume of ice cold water maintained at $4{ }^{\circ} \mathrm{C}$. The resulting lipospheres were separated by filtration, washed with ice cold water and dried at room temperature $\left(25^{\circ} \mathrm{C}\right)$ for 24 hours. A total of 9 batches (F1 to F9) of glipizide lipospheres were produced as per $3^{2}$ full factorial design by varying the drug to wax ratio and levels of stearic acid (Table I). The other formulation and processing variables were maintained constant during the process.

Table I. Composition of glipizide lipospheres prepared as per $3^{2}$ factorial design

\begin{tabular}{cccc}
\hline $\begin{array}{c}\text { Batch } \\
\text { code }\end{array}$ & $\begin{array}{c}\text { Glipizide } \\
(\%, m / m)\end{array}$ & $\begin{array}{c}\text { Paraffin wax } \\
(\%, m / m)\end{array}$ & $\begin{array}{c}\text { Stearic acid } \\
(\%, m / m)\end{array}$ \\
\hline F1 & 75 & 25 & 0 \\
F2 & 50 & 50 & 0 \\
F3 & 25 & 75 & 0 \\
F4 & 75 & 20 & 5 \\
F5 & 50 & 40 & 10 \\
F6 & 25 & 60 & 15 \\
F7 & 75 & 15 & 10 \\
F8 & 50 & 30 & 20 \\
F9 & 25 & 45 & 30 \\
\hline
\end{tabular}

\section{Characterization of lipospheres}

Particle size distribution. - The number distribution of different batches of lipospheres was determined by optical microscopy (4). The projected diameter of a total of 200 lipospheres from each batch was determined using an image analyzer (Labomed, India) that consisted of a optical microscope linked to a computer and a digital camera. The digitalized images captured were analyzed by image analyzing software (Digipro version 2, Labomed). The geometric mean diameter $\left(d_{\mathrm{g}}\right)$ and standard deviation $\left(\sigma_{\mathrm{g}}\right)$ were computed by fitting the number distribution data into log normal plots (11).

Encapsulation efficiency. - An accurately weighed quantity of drug loaded lipospheres was pulverized and digested in sodium hydroxide $\left(0.1 \mathrm{~mol} \mathrm{~L}^{-1}\right)$. The drug was extracted with the solvent overnight, filtered and the amount of glipizide in the filtrate was assayed after appropriate dilution by measuring the absorbance at $223 \mathrm{~nm}$ in a UV-visible 
spectrophotometer (Shimadzu UV 1700 PC, Shimadzu, Japan). The drug content was estimated in triplicate using a calibration curve constructed in the same solvent (9). The percentage encapsulation efficiency of different batches of lipospheres was calculated from the percentage drug content values.

In vitro drug release studies. - Dissolution studies were performed over a period of 12 hours in a USP XXIV (12) basket dissolution apparatus [TDL-08 L, Electrolab (I) Ltd., India] at a stirring speed of $100 \mathrm{rpm}$. Release studies of the glipizide and drug loaded lipospheres were carried out using phosphate buffer of pH $7.4(900 \mathrm{~mL})$, maintained at $37 \pm$ $0.5^{\circ} \mathrm{C}$, as a dissolution medium (9). Aliquots of samples withdrawn every hour were filtered though $0.45-\mu \mathrm{m}$ filter, appropriately diluted, and assayed spectrophotometrically at $223 \mathrm{~nm}$. The raw dissolution data recorded in triplicate was analyzed to calculate the percentage of cumulative drug released at different time intervals.

Data fitting. - An attempt was made to fit the dissolution data into the Higuchi diffusion model (13) represented:

$$
M_{\mathrm{t}}=K t^{0.5}
$$

$M_{t}$ stands for the amount of drug released at $\sqrt{t}$ and $K_{H}$ is the Higuchi rate constant. The data was also treated with the Korsmeyer-Peppas model (14) to characterize the mechanism of drug release:

$$
\frac{M_{\mathrm{t}}}{M_{\infty}}=K_{\mathrm{P}} t^{n}
$$

$M_{t} / M_{\infty}$ represents the fraction of drug released at time $t$ and $K_{p}$ is the kinetic constant characterizing the polymeric system and $n$ stands for the diffusion exponent.

The dissolution data was also analyzed using the first-order equation (15) to determine the kinetics of drug release from different batches of lipospheres:

$$
\log Q_{\mathrm{t}}=\log Q_{0}+\frac{K_{1} t}{2.303}
$$

The curve fitting, simulation and plotting was performed in Excel (Microsoft Software Inc., USA) and Graph Pad Prism ${ }^{\circledR}$ version 3.02 (Graph Pad Software Inc., USA).

Regression analysis. - The targeted response parameters were statistically analyzed by applying one-way ANOVA at 0.05 level in the Design-Expert ${ }^{\circledR}$ 6.0.5 demo version soft ware (Stat-Ease Inc., USA). Individual response parameters were evaluated using the F-test and quadratic models of the form given below were generated for each response parameter using the multiple linear regression analysis (16):

$$
Y=\beta_{0}+\beta_{1} X_{1}+\beta_{2} X_{2}+\beta_{3} X_{1} X_{2}+\beta_{4} X_{1}^{2}+\beta_{5} X_{2}^{2}
$$

where $Y$ is the level of the measured response, $\beta_{0}$ is the intercept, $\beta_{1}$ to $\beta_{5}$ are the regression coefficients, $X_{1}$ and $X_{2}$ stand for the main effects, $X_{1} X_{2}$ is the interaction between the main effects, $X_{1}^{2}$ and $X_{2}^{2}$ are the quadratic terms of the independent variables that were used to simulate the curvature of the designed sample space. A backward elimination procedure was adopted to fit the data to the quadratic model. The quadratic models ge- 
nerated from the regression analysis were used to construct the 3-dimensional graphs, in which the response parameter $Y$ was represented by a curvature surface as a function of $X$. The effects of independent variables on the response parameters were visualized from the contour plots.

Numerical optimization using the desirability approach was employed to locate the optimal settings of the formulation variables to obtain the desired response (16). An optimized formulation was developed by setting constraints on the dependent and independent variables. The formulation developed was evaluated for the responses and the experimental values obtained were compared with those predicted by the mathematical models generated.

Scanning electron microscopy. - Morphology and surface topography of the lipospheres were examined by scanning electron microscopy (3). The lipospheres from the optimized batch (F10) were mounted on the SEM sample stab using a double-sided sticking tape and coated with gold $(\sim 200 \mathrm{~nm})$ under reduced pressure $(0.133 \mathrm{~Pa})$ for $5 \mathrm{~min}$ using an Ion sputtering device (JFC-1100 E, JEOL, Japan). The gold coated lipospheres were observed under the scanning electron microscope (JSM-840 A, JEOL) and photomicrographs of suitable magnifications was obtained.

Differential scanning calorimetry. - Thermograms of glipizide, placebo lipospheres and optimized liposphere formulation (F10) were recorded in a differential scanning calorimeter (Pyris-1, Perkin Elmer, USA) to characterize the solid state of the drug in the wax matrix. The samples were placed in flat bottomed aluminum pans and heated over a temperature range of $40-180{ }^{\circ} \mathrm{C}$ at a constant rate of $5{ }^{\circ} \mathrm{C} \mathrm{min}-1$ with purging of nitrogen $\left(50 \mathrm{~mL} \mathrm{~min}^{-1}\right)$, using alumina as a reference standard.

In vivo study. - In vivo evaluation of glipizide lipospheres was performed on healthy albino Wistar rats weighing between 250 and $300 \mathrm{~g}$ (8). Approval of the Institutional Animal Ethics Committee was obtained before the study. Two groups of rats (4 in each group) fasted for 12 hours with free access to water were used for the study. Stock suspensions of either the drug or the drug loaded lipospheres containing glipizide at a concentration of $200 \mu \mathrm{g} \mathrm{mL}^{-1}$ were used for oral administration. The suspensions were administered orally at a dose equivalent to $800 \mu \mathrm{g} \mathrm{kg}^{-1}$ of glipizide to respective groups using stomach intubation. Blood samples were withdrawn at predetermined time intervals of $0,1,2,4$, $6,8,10,12$ and 24 hours by retroorbital puncture. The blood sample withdrawn at time 0 was considered as control. The blood glucose level of the control and test samples were determined using the glucose-measuring instrument Accu-check active (Roche Diagnostics, USA). The percentage reduction in blood glucose levels was computed and plotted against time.

\section{RESULTS AND DISCUSSION}

The melt dispersion technique employed to produce drug loaded lipospheres is ideal for encapsulation of water insoluble drugs (4). Due to its poor aqueous solubility (6), glipizide was selected as drug candidate to prepare lipospheres employing the melt dispersion technique. Since lipospheres produced with paraffin wax alone resulted in poor drug release, efforts were made to enhance drug release from the lipospheres by incor- 
porating a wax modifier like stearic acid. Literature citations reveal that stearic acid has been successfully employed as a wax modifier to modulate drug release from wax microspheres (3). Tween 80 was used to stabilize the oil in water emulsion by reducing the interfacial tension between the hydrophobic wax dispersion and the external aqueous phase, producing an emulsified oily dispersion, which resulted in drug loaded lipospheres on cooling.

The independent variables and their levels were selected based on the preliminary trials undertaken. The trials revealed that low wax payloads $(<20 \%)$ failed to produce lipospheres with acceptable physical characteristics whereas high wax loads $(>80 \%)$ resulted in lipospheres that exhibited poor drug release $(<40 \%$ at the end of $12 \mathrm{~h})$. Based on these observations, the lower and higher levels of percentage drug loading were retained at $25 \%$ and $75 \%$, respectively, during the run.

As drug release from the lipospheres with paraffin wax alone was inherently sustained, stearic acid was used as a wax modifier. Since stearic acid at concentrations exceeding $50 \%$ of wax load resulted in poor encapsulation efficiencies $(<80 \%)$, the lower and higher levels of the wax modifier were maintained at 0 and $40 \%$ of the total wax loads, respectively, during the run.

The other formulation variables, such as the amount of emulsifier, volume of the external aqueous phase and the processing variables like stirring speed, stirring time and the temperature of emulsification, were maintained constant during the study.

SEM photomicrographs (Fig. 1a) revealed that the optimized liposphere formulations (F10) were more or less spherical with a rough surface. Numerous drug crystals were clearly evident under high magnification (Fig. 1b) which can be attributed to the high drug loads in the lipospheres. The drug crystallized on the surface of the lipospheres once the drug concentration in the lipospheres exceeded its solubility in the wax matrix.

Optical microscopic image analysis revealed that the lipospheres of different batches exhibited a narrow size distribution, with particles ranging in size between 20 to $150 \mu \mathrm{m}$. The number distribution data obtained when represented as log-probability plots gave straight lines, indicating a log-normal distribution for all batches of the lipospheres produced. The geometric mean diameters for different batches of lipospheres were found to
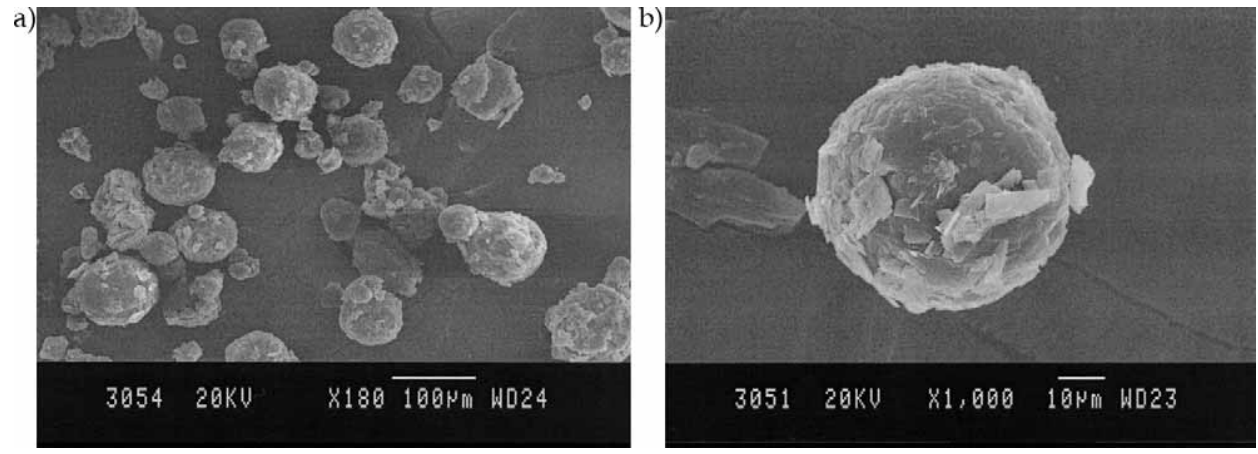

Fig. 1. Scanning photomicrographs of glipizide lipospheres: a) under low magnification, b) under high magnification. 
H. N. Shivakumar et al.: Design and statistical optimization of glipizide loaded lipospheres using response surface methodology, Acta Pharm. 57 (2007) 269-285.

Table II. Factor combinations and response parameters of glipizide lipospheres prepared as per $3^{2}$ factorial design

\begin{tabular}{ccccccr}
\hline $\begin{array}{c}\text { Batch } \\
\text { code }\end{array}$ & $\mathrm{X}_{1}^{\mathrm{a}}$ & $\mathrm{X}_{2}^{\mathrm{a}}$ & $\begin{array}{c}d_{\mathrm{g}} \\
(\mu \mathrm{m})\end{array}$ & $\begin{array}{c}E E^{\mathrm{b}} \\
(\%, m / m)\end{array}$ & $\begin{array}{c}\mathrm{rel}_{12} \mathrm{~b} \\
(\%)\end{array}$ & \multicolumn{1}{c}{$\begin{array}{c}t_{50} \mathrm{~b} \\
(\mathrm{~h})\end{array}$} \\
\hline F1 & $-1(25)$ & $-1(0)$ & $52.48 \pm 1.38$ & $87.12 \pm 1.44$ & $63.89 \pm 2.32$ & $8.57 \pm 0.55$ \\
F2 & $0(50)$ & $-1(0)$ & $63.10 \pm 1.38$ & $92.23 \pm 0.82$ & $55.09 \pm 2.34$ & $10.80 \pm 0.60$ \\
F3 & $+1(75)$ & $-1(0)$ & $69.18 \pm 1.45$ & $95.66 \pm 0.99$ & $51.18 \pm 1.14$ & $11.60 \pm 0.40$ \\
F4 & $-1(25)$ & $0(20)$ & $50.12 \pm 1.32$ & $88.46 \pm 1.47$ & $87.89 \pm 2.26$ & $4.33 \pm 0.25$ \\
F5 & $0(50)$ & $0(20)$ & $57.54 \pm 1.44$ & $89.12 \pm 0.98$ & $76.47 \pm 2.32$ & $7.63 \pm 0.45$ \\
F6 & $+1(75)$ & $0(20)$ & $66.07 \pm 1.38$ & $92.45 \pm 1.62$ & $66.12 \pm 2.48$ & $8.33 \pm 0.45$ \\
F7 & $-1(25)$ & $+1(40)$ & $47.86 \pm 1.32$ & $82.76 \pm 1.11$ & $91.26 \pm 4.77$ & $4.37 \pm 0.31$ \\
F8 & $0(50)$ & $+1(40)$ & $54.95 \pm 1.38$ & $86.24 \pm 1.55$ & $83.21 \pm 2.58$ & $4.60 \pm 0.30$ \\
F9 & $+1(75)$ & $+1(40)$ & $60.26 \pm 1.44$ & $90.66 \pm 1.73$ & $76.52 \pm 3.14$ & $6.07 \pm 0.60$ \\
\hline
\end{tabular}

$\mathrm{X}_{1}$ - percent wax load, $\mathrm{X}_{2}$ - percent of stearic acid in the wax, $d_{\mathrm{g}}$ - geometric mean diameter, $E E$ - encapsulation efficiency, $r e l_{12}$ - release at the end of $12 \mathrm{~h}, t_{50}$ - time taken for $50 \%$ of the drug release.

a The parentheses in the data represent the decoded factor levels.

b Mean $\pm \mathrm{SD}, n=3$.

range from 47.86 to $69.18 \mu \mathrm{m}$. The corresponding standard deviation values ranged between 1.32 and 1.44 (Table II).

High encapsulation efficiencies ranging from $82.76 \pm 1.11 \%$ to $95.66 \pm 0.99 \%$ (Table II) were recorded for different batches of lipospheres produced. The values indicated that the drug encapsulation depended on the levels of wax as well as on wax composition, which influenced the drug wax compatibility. The high values of encapsulation efficiency can also be ascribed to the lipophilic nature of the drug, which got easily wetted and finely dispersed in the molten wax phase prior to emulsification.

The amount of drug released from the lipospheres at the end of $12 \mathrm{~h}$ of dissolution are shown in Table II along with the $t_{50}$ values. As mentioned earlier, the $\mathrm{p} K_{\mathrm{a}}$ of glipizide is reported to be 5.9. The solubility is found to increase significantly above the $\mathrm{p} K_{\mathrm{a}}$ value of the drug. Considering this, the USP recommends to study the dissolution at $\mathrm{pH} 6.8$ buffer (12). Since under these $\mathrm{pH}$ conditions the sink conditions are not fully met (18), the dissolution studies were performed at $\mathrm{pH} 7.4$ so as to ensure that the sink conditions are met. The drug release profiles of glipizide and drug loaded lipospheres are shown in Fig. 2. Drug release from the lipospheres depended on the wax payloads and the stearic acid levels. Lipospheres produced with paraffin wax alone showed slow drug release, ranging from $50.18 \pm 2.35 \%$ to $63.89 \pm 2.19 \%$, by the end of $12 \mathrm{~h}$ of dissolution. The slow release indicated efficient encapsulation of the lipophilic drug in the wax, resulting in a compact dense wax matrix that posed a significant hindrance to fluid penetration and passive drug diffusion.

Even though diffusional systems are supposed to be a poor choice for slightly soluble drugs (18), a microporous matrix system in the form of wax microspheres is reported to be an ideal choice for poorly water-soluble drugs (15). Incorporation of stearic acid is reported to render the liposphere microporous and enhance the release of the poorly solu- 
Fig. 2. In vitro drug release from glipizide and drug loaded lipospheres prepared as per 32 factorial design (mean $\pm \mathrm{SD}, n=3)$.

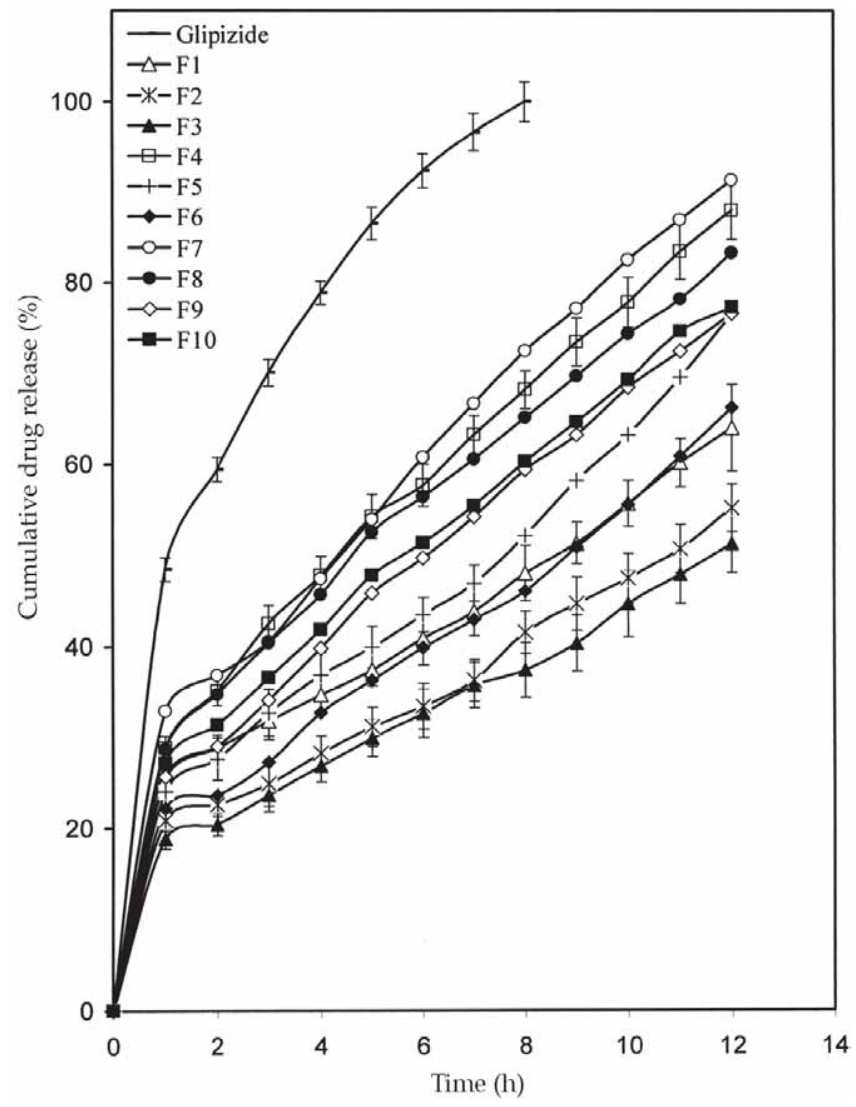

ble drug (3). The drug release from lipospheres in which $20 \%$ of the wax is replaced with stearic acid was found to range from $66.12 \pm 3.25 \%$ to $87.89 \pm 0.73 \%$ after 12 hours of dissolution, indicating enhancement of drug release in the presence of the modifier. Lipospheres in which $40 \%$ of the wax was substituted with stearic acid further enhanced the drug release since $76.52 \pm 3.54 \%$ to $91.26 \pm 1.89 \%$ of the drug was released at the end of the dissolution period.

The predictor equation generated for the geometric mean diameter $\left(d_{g}\right)$ was found to be significant with an $F$-value of $132.24(p<0.0001)$ and $R^{2}$ value of 0.9778 :

$$
\mathrm{Y}_{1}=57.95+7.51 \mathrm{X}_{1}-3.62 \mathrm{X}_{2}
$$

The equation generated revealed that both main factors independently exerted a significant influence on the mean diameter. The influence of the main effects on the particle size of the lipospheres was further elucidated using the response surface plot (Fig. 3a). The mean diameter increased from $52.48 \pm 1.38 \mu \mathrm{m}$ to $69.18 \pm 1.45 \mu \mathrm{m}$ and from 47.86 $\pm 1.32 \mu \mathrm{m}$ to $60.26 \pm 1.44 \mu \mathrm{m}$ at lower and higher levels of stearic acid, respectively, as 
the wax loads increased. This was probably due to the inherent tackiness of the wax, leading to larger particles as the wax loads increased. An increase in the particle size of wax microspheres at higher wax loads was reported earlier (19).

The liposphere size reduced from $69.18 \pm 1.45 \mu \mathrm{m}$ to $60.26 \pm 1.44 \mu \mathrm{m}$ and from 52.48 $\pm 1.38 \mu \mathrm{m}$ to $47.86 \pm 1.32 \mu \mathrm{m}$ at high and low wax loads, respectively, as the stearic acid levels increased. This could be attributed to the drop in viscosity of the dispersed wax phase on incorporation of the low viscosity melt, which resulted in formation of smaller droplets of the drug wax suspension during emulsification (3). The corresponding contour plots were linear and indicated that the number of fins can be minimized using higher wax loads coupled with lower stearic acid levels.

The linear model generated for encapsulation efficiency was found to be significant with an $F$-value of $34.42(p<0.0005)$ and $R^{2}$ value of 0.9198 :

$$
\mathrm{Y}_{2}=89.41+3.40 \mathrm{X}_{1}-2.56 \mathrm{X}_{2}
$$

The model indicated that both the factors studied exerted independently a significant influence on the encapsulation efficiency. The 3-D plot (Fig. 3b) shows that the en-

a)

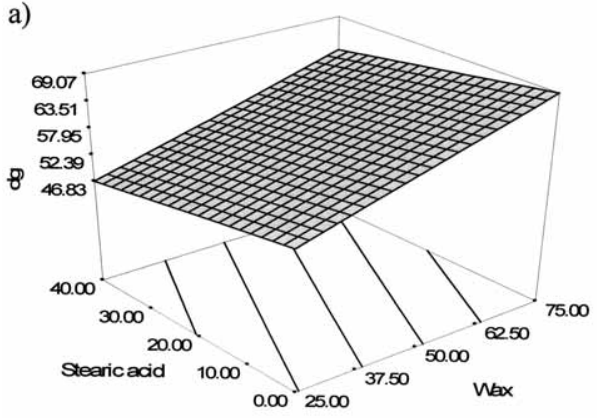

c)

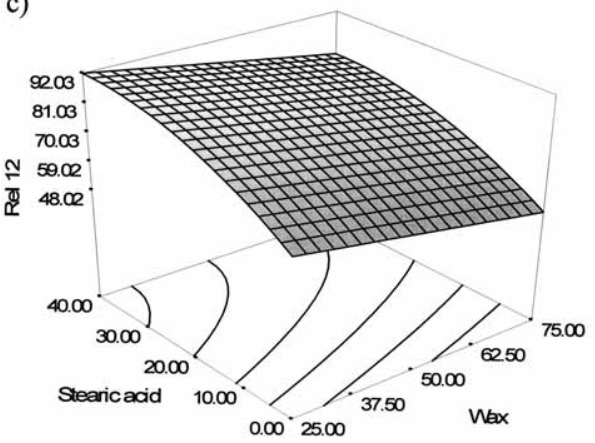

b)

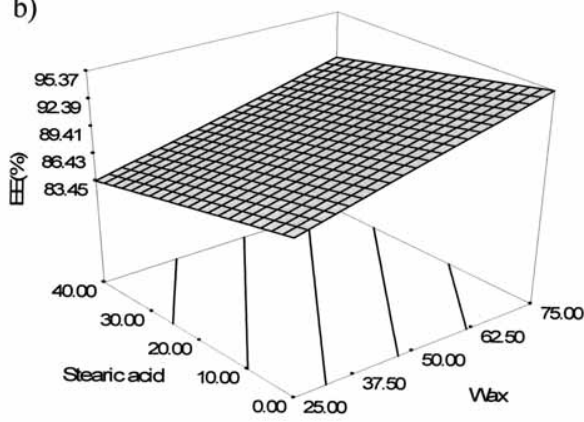

d)

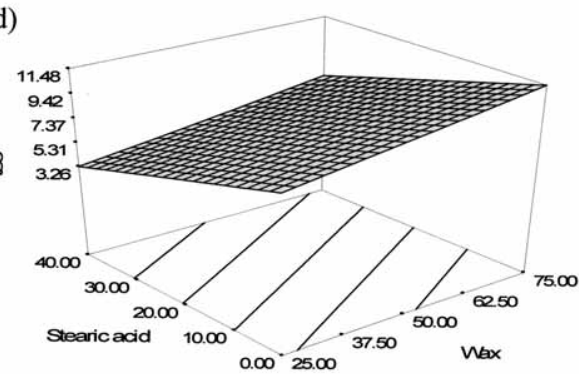

Fig. 3. Response surface plot showing the effect of wax loads $\left(X_{1}\right)$ and stearic acid levels $\left(X_{2}\right)$ on: a) mean diameter $\left.\left(Y_{1}\right), b\right)$ encapsulation efficiency $\left(Y_{2}\right)$, c) release at the end of 12 hours $\left(Y_{3}\right)$, and $\left.d\right)$ time taken for $50 \%$ drug release $\left(\mathrm{Y}_{4}\right)$. 
capsulation efficiency increased from $87.12 \pm 1.44 \%$ to $95.66 \pm 0.99 \%$ and from $82.76 \pm$ $1.11 \%$ to $90.66 \pm 1.73 \%$ at lower and higher levels of stearic acid, respectively, as the wax levels increased. This improvement in encapsulation efficiency with an increase in wax levels was due to efficient wetting and dispersion of the drug in the molten wax at higher wax loads. In contrast, encapsulation efficiency declined from $87.12 \pm 1.44 \%$ to $82.76 \pm$ $1.11 \%$ and from $95.66 \pm 0.99 \%$ to $90.66 \pm 1.73 \%$ at high and low wax loads, respectively, as stearic acid levels increased, which could be due to the presence of the carboxylic group in stearic acid, which resulted in poor wetting of the hydrophobic drug in the molten wax (3). This caused inadequate dispersion of the drug in the molten wax, resulting in lower drug encapsulation at higher stearic acid levels. As a consequence, drug crystals were visible on the outer surface of the lipospheres at higher stearic acid levels. A linear relationship between the two variables of encapsulation efficiency was clearly visible from the corresponding contour plots, which suggested that encapsulation efficiency can be enhanced using low stearic acid levels at high wax loads.

The second order polynomial model generated for release at the end of $12 \mathrm{~h}$ was significant with $F$-value of $121.95(p<0.0001)$ and $R^{2}$ value of 0.9865 :

$$
Y_{3}=76.83-8.37 X_{1}+13.64 X_{2}-6.80 X_{2}^{2}
$$

The quadratic model generated revealed that the levels of wax and stearic acid had a significant antagonistic influence on the drug release, without producing any interaction. The wax loads were found to have a negative influence on the drug release since glipizide release at the end of 12 hours of dissolution showed a decline with an increase in the levels of wax. The response surface plots (Fig. 3c) illustrate that the drug release at the end of 12 hours decreased from $63.89 \pm 2.19 \%$ to $50.18 \pm 2.35 \%$ and from $91.26 \pm$ $1.89 \%$ to $76.52 \pm 3.54 \%$ at low and high levels of stearic acid, respectively, as the wax loads increased. The quicker drug release at low wax loads can be due to increased drug crystals positioned on the liposphere surface that remained exposed to the dissolution fluid (3). At higher drug loads, drug dissolution resulted in a subsequent increase in the number of channels and pores within the wax matrix, which decreased the diffusional path length through the drug depleted zone and enhanced drug release (20).

Stearic acid levels were found to have a positive influence on drug release since the drug release improved on incorporation of stearic acid. It was evident from the 3-D plots that the drug release at the end of 12 hours enhanced from $63.89 \pm 2.19 \%$ to $91.26 \pm 1.89 \%$ and from $50.18 \pm 2.35 \%$ to $76.52 \pm 3.54 \%$ at low and high wax levels, respectively, as the stearic acid levels increased. This enhancement in drug release can be ascribed to the polar carboxylic acid groups in stearic acid, which made the matrix more susceptible to hydration and thereby created a hydrophilic pathway for water molecules to access the drug (20). This decreased the resistance to diffusion of the dissolution fluid through the wax matrix and increased the drug dissolution. The lower melting point and density of stearic acid also reported to be contributing factors to enhancing the drug release from the heterogeneous wax matrix systems (21). The corresponding contour plots illustrate that the drug release at the end of 12 hours can be maximized by using low wax loads coupled with high stearic acid levels.

The mathematical model generated for time taken for $50 \%$ drug release was found to be significant with $F$-value of $35.14(p<0.0005)$ and $R^{2}$ value of 0.9213 : 
H. N. Shivakumar et al.: Design and statistical optimization of glipizide loaded lipospheres using response surface methodology, Acta Pharm. 57 (2007) 269-285.

$$
\mathrm{Y}_{4}=7.47+1.46 \mathrm{X}_{1}-2.66 \mathrm{X}_{2}
$$

The mathematical model generated indicated that both the wax loads and stearic acid levels were found to exert independently a significant influence on $t_{50}$. The positive influence of wax levels on $t_{50}$ is clearly demonstrated by the response surface plots (Fig. $3 \mathrm{~d}$ ), which indicate that the $t_{50}$ increased from $8.57 \pm 0.55$ hours to $11.60 \pm 0.40$ hours and from $4.33 \pm 0.25$ hours to $6.07 \pm 0.60$ hours at low and high stearic acid levels, respectively, as the wax loads increased. The slower drug release with increased wax loads was due to better encapsulation of the lipophilic drug in the wax matrix, which resulted in high $t_{50}$ values. The 3 -D plots also show that the $t_{50}$ reduced $8.57 \pm 0.55$ hours to $4.33 \pm$ 0.25 hours and from $11.60 \pm 0.40$ hours and $6.07 \pm 0.60$ hours at lower and higher wax loads as the stearic acid content increased, namely from $8.57 \pm 0.55$ hours to $4.33 \pm 0.25$ hours and from $11.60 \pm 0.40$ hours to $6.07 \pm 0.60$ hours at lower and higher wax loads, respectively. This can be attributed to the hydrophilic and leaching property of stearic acid, which increased the magnitude of the voids and consequently the channels from the liposphere surface, resulting in the formation of a heavily structured, and microporous matrix (3). The corresponding contour plots indicated a linear relationship between the two variables investigated and $t_{50}$. It was evident from the contour plots that $t_{50}$ can be minimized using low wax loads with high levels of stearic acid.

The results of curve fitting into different mathematical models are given in Table III. The mechanism of drug release from the lipospheres was found to be diffusion controlled because plots of percent cumulative drug release $v$ s. square root of time were found to be linear with the regression coefficient $\left(R^{2}\right)$ values ranging from 0.950 to 0.990 for the nine formulations. The value of the Higuchi rate constant (13) was found to vary between $13.37 \pm 0.31$ to $25.47 \pm 0.95 \mathrm{~h}^{-1 / 2}$, showing an increasing trend as the wax level de-

Table III. Results of curve fitting of the dissolution data for the lipospheres prepared as per $3^{2}$ factorial design

\begin{tabular}{|c|c|c|c|c|}
\hline \multirow{2}{*}{ Batch code } & \multicolumn{2}{|c|}{ Korsmeyer Peppas } & \multirow{2}{*}{$\begin{array}{c}\text { Higuchi } \\
K_{\mathrm{H}}\left(\% \mathrm{~h}^{-1 / 2}\right)^{\mathrm{a}}\end{array}$} & \multirow{2}{*}{$\begin{array}{c}\text { First-order } \\
K_{1}^{\mathrm{a}}\left(\mathrm{h}^{-1}\right)\end{array}$} \\
\hline & $n^{\mathrm{a}}$ & $K_{\mathrm{P}}\left(\mathrm{h}^{-\mathrm{n}}\right)^{\mathrm{a}}$ & & \\
\hline F1 & $0.34 \pm 0.02$ & $0.528 \pm 0.006$ & $15.64 \pm 1.30$ & $0.066 \pm 0.001$ \\
\hline F2 & $0.41 \pm 0.01$ & $0.467 \pm 0.005$ & $14.19 \pm 0.60$ & $0.055 \pm 0.001$ \\
\hline F3 & $0.42 \pm 0.01$ & $0.446 \pm 0.006$ & $13.37 \pm 0.31$ & $0.051 \pm 0.001$ \\
\hline F4 & $0.38 \pm 0.02$ & $0.572 \pm 0.007$ & $24.22 \pm 0.49$ & $0.140 \pm 0.001$ \\
\hline F5 & $0.37 \pm 0.04$ & $0.514 \pm 0.011$ & $20.67 \pm 0.45$ & $0.092 \pm 0.001$ \\
\hline F6 & $0.41 \pm 0.03$ & $0.481 \pm 0.009$ & $17.97 \pm 0.54$ & $0.071 \pm 0.001$ \\
\hline F7 & $0.28 \pm 0.04$ & $0.599 \pm 0.010$ & $25.47 \pm 0.94$ & $0.155 \pm 0.002$ \\
\hline F8 & $0.36 \pm 0.03$ & $0.568 \pm 0.008$ & $22.36 \pm 0.63$ & $0.119 \pm 0.002$ \\
\hline F9 & $0.39 \pm 0.03$ & $0.529 \pm 0.008$ & $21.62 \pm 1.01$ & $0.097 \pm 0.001$ \\
\hline
\end{tabular}

$n$ - diffusion exponent, $K_{\mathrm{P}}$ - kinetic constant, $K_{\mathrm{H}}$ - Higuchi rate constant, $K_{1}$ - first-order rate constant.

${ }^{\text {a }}$ Mean $\pm \mathrm{SD}, n=3$. 
creased and stearic acid level increased. Since the liposphere size did not change after complete exhaustion of the drug during dissolution, the release data representing the first $60 \%$ of the drug release was further analyzed using the Korsmeyer-Peppas equation (14) to further characterize the diffusional release. The Korsmeyer-Peppas model has been employed to distinguish between the two competing release mechanisms, a Fickian (non-steady) diffusional release when $n \leq 0.43$ and a case-II transport (zero-order kinetics) when $n \geq 0.85$ (14). The low values of the diffusion exponent $(0.28 \pm 0.04$ to $0.42 \pm 0.01)$ indicated the Fickian diffusional release and at the same time ruled out the possibilities of erosion or solubilization of the wax matrix.

The kinetics of drug release from the liposphere was found to follow first-order kinetics (15) as the plots of log concentration of drug retained vs. time were linear $\left(R^{2}\right.$ value ranged from 0.941 to 0.982 ) with the values of the first-order rate constant ranging from $0.055 \pm 0.001$ to $0.155 \pm 0.002 \mathrm{~h}^{-1}$.

The results of ANOVA, as shown in Table IV, indicated that the model was significant for all response parameters investigated. The multiple linear regression analysis performed revealed that both the formulation variables analyzed had a significant influence on all response parameters. The results obtained collectively indicate that optimum amounts of wax and wax modifier are essential to produce lipospheres with desirable encapsulation and release characteristics.

Table IV. Summary of ANOVA for the response parameters of lipospheres prepared as per $3^{2}$ factorial design

\begin{tabular}{ccrrrc}
\hline Source & d.f. & Sum square & Mean square & $F$-value & Probability $>F$ \\
\hline$d_{\mathrm{g}}(\mu \mathrm{m})$ & & & & & $R^{2}=0.9778$ \\
Model & 2 & 416.66 & 208.33 & 132.24 & $<0.0001$ \\
$\mathrm{X}_{1}$ & 1 & 338.25 & 338.25 & 214.71 & $<0.0001$ \\
$\mathrm{X}_{2}$ & 1 & 78.41 & 78.41 & 49.77 & 0.0004 \\
$E E(\%)$ & & & & $R^{2}=0.9198$ \\
Model & 2 & 108.83 & 54.42 & 34.42 & 0.0005 \\
$\mathrm{X}_{1}$ & 1 & 69.56 & 69.56 & 44.00 & 0.0006 \\
$\mathrm{X}_{2}$ & 1 & 39.27 & 39.27 & 24.84 & 0.0025 \\
Rel $_{12}(\%)$ & & & & & $R^{2}=0.9865$ \\
Model & 3 & 1628.89 & 542.96 & 121.95 & $<0.0001$ \\
$\mathrm{X}_{1}$ & 1 & 420.34 & 420.34 & 94.41 & 0.0002 \\
$\mathrm{X}_{2}$ & 1 & 1116.02 & 1116.04 & 250.66 & $<0.0001$ \\
$\mathrm{X}_{2}$ & 1 & 92.53 & 92.53 & 20.78 & 0.0061 \\
$t_{50}(\mathrm{~h})$ & & & & & $R^{2}=0.9317$ \\
Model & 2 & 59.55 & 29.78 & 40.91 & 0.0003 \\
$\mathrm{X}_{1}$ & 1 & 14.73 & 14.73 & 20.24 & 0.0041 \\
$\mathrm{X}_{2}$ & 1 & 44.83 & 44.83 & 61.59 & 0.0002 \\
\hline
\end{tabular}

$X_{1}$ - percent wax loads, $X_{2}$ - percent of stearic acid in the wax, $X_{2}^{2}-$ quadratic term of $X_{2}$. 
H. N. Shivakumar et al.: Design and statistical optimization of glipizide loaded lipospheres using response surface methodology, Acta Pharm. 57 (2007) 269-285.

Table V. Comparison of experimentally observed responses of the optimized liposphere formulation with that of predicted responses

\begin{tabular}{ccccc}
\hline Response parameters & Constraints set & Observed values $^{\mathrm{a}}$ & Predicted values & Error $(\%)^{(\%)}$ \\
\hline$d_{\mathrm{g}}(\mu \mathrm{m})$ & in the range & $57.54 \pm 1.38$ & 59.06 & 2.6 \\
$E E(\%, m / m)$ & maximize & $86.28 \pm 1.32$ & 89.00 & 3.2 \\
rel $_{12}(\%)$ & maximize & $77.23 \pm 2.78$ & 78.39 & 1.5 \\
$t_{50}(\mathrm{~h})$ & minimize & $5.60 \pm 0.32$ & 5.72 & 2.1 \\
\hline
\end{tabular}

Absolute error $2.4 \pm 0.7$

a Mean $\pm \mathrm{SD}, n=3$.

A numerical optimization technique using the desirability approach was employed to develop a new formulation with the desired responses. Constraints like maximizing the encapsulation efficiency and release at the end of 12 hours in addition to minimizing the $t_{50}$ were set as goals to locate the optimum settings of independent variables in the new formulation.

The optimized liposphere formulation (F10) was developed using 34.3\% of glipizide, $39.4 \%$ of paraffin wax and $26.3 \%$ of stearic acid. The optimized formulation was evaluated for particle size, encapsulation efficiency and drug release. Table $\mathrm{V}$ lists the values of the observed responses and those predicted by mathematical models along with the percentage prediction errors. The prediction error for the response parameters ranged between 1.50 and $3.15 \%$ with the value of absolute error of $2.36 \pm 0.70 \%$. The low values of error indicate the high prognostic ability of response surface methodology. Model reduction using MLRA by eliminating insignificant terms has already been reported to result in better prognosis of the performance of the optimized formulation (16). The drug release from the optimized formulation was found to follow first-order kinetics and was characterized by the Fickian diffusion model.

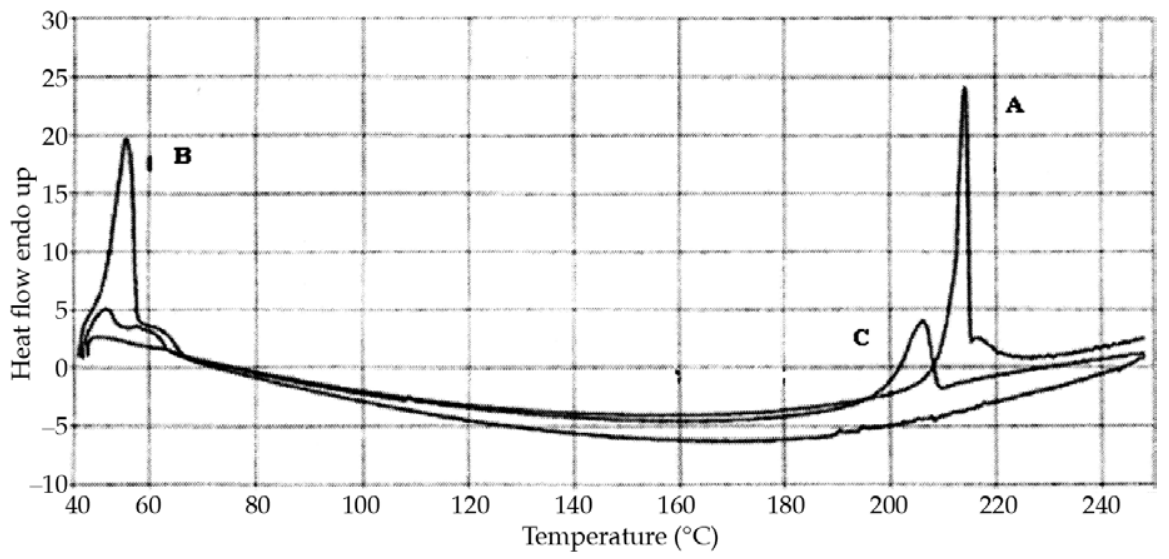

Fig. 4. Differential scanning calorimetric thermograms of: glipizide (A), placebo lipospheres (B) and optimized liposphere formulation $(C)$. 
Fig. 5. Percentage reduction in serum glucose levels following oral administration of glipizide and the optimized liposphere formulation (mean $\pm \mathrm{SD}, n=4$ ).

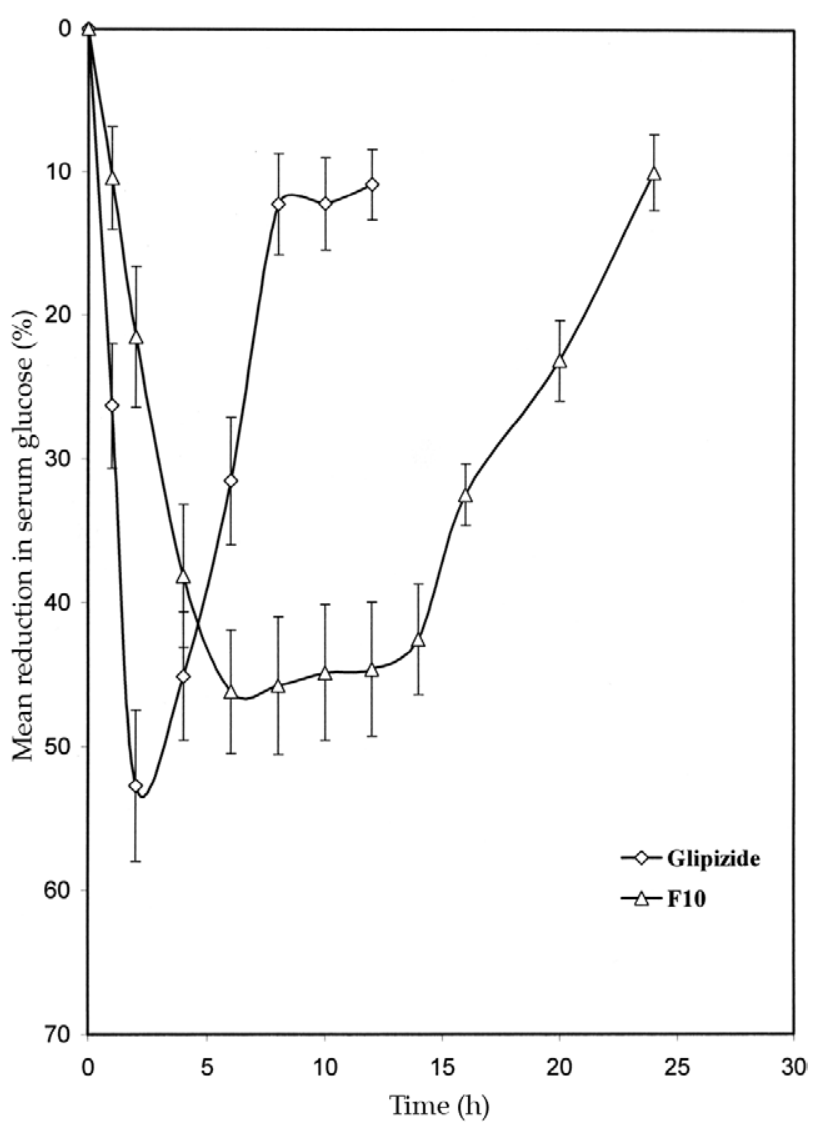

Differential scanning analysis was performed to characterize the solid state of the drug in the wax matrix. The DSC thermogram of glipizide exhibited a sharp endothermic peak at $212{ }^{\circ} \mathrm{C}$ corresponding to its melting transition point (Fig. 4). The thermogram of the placebo liposphere formulation displays a sharp peak at $58{ }^{\circ} \mathrm{C}$ corresponding to the melting point of the stearic acid-paraffin wax mixture. This clearly indicated the lowering of the melting point of paraffin wax (melting point $62{ }^{\circ} \mathrm{C}$ ) in the presence of stearic acid. The appearance of the sharp low intensity endothermic peak in the thermogram of the optimized liposphere formulation (F10) at $206^{\circ} \mathrm{C}$ suggested that the drug may be present in the molecular as well as microcrystalline state in the wax matrix, which could also explain the sustained drug release from the liposphere formulations.

In vivo efficiency tests of the pure glipizide and optimized liposphere formulation (F10) were performed on albino Wistar rats by measuring the hypoglycemic effect produced after oral administration. Pure glipizide and the optimized liposphere formulation were administered at a dose equivalent to $800 \mu \mathrm{g} \mathrm{kg}-1$. With pure glipizide, a rapid reduction in blood glucose levels was observed with maximum reduction of $52.72 \pm 5.26 \%$ within 2 hours after 
oral administration. Following the drug administration, the blood glucose levels recovered to normal within 8 hours in case of the pure drug (Fig. 5). The reduction in blood glucose levels was gradual and reached maximum reduction $(46.22 \pm 4.31 \%) 6$ hours after the administration of optimized glipizide lipospheres. This reduction in blood glucose levels was sustained for longer periods of time (16 hours). A $25 \%$ reduction in blood glucose levels is considered a significant hypoglycemic effect (22). Significant hypoglycemic effect was observed between 1 and 6 hours after oral administration of glipizide, whereas with lipospheres, a significant hypoglycemic effect was maintained for 3 to 16 hours after administration. One can speculate that the glipizide particles are voided from the stomach much quicker than the lipospheres, and then they immediately dissolve in the duodenal fluid with higher $\mathrm{pH}$ and get absorbed. This may not be the case with the drug loaded lipospheres, where the sustained hypoglycemic effect may be due to longer gastric transit time and slower release of glipizide in the duodenum.

\section{CONCLUSIONS}

The modified hydrophobic congealable dispersed phase encapsulation procedure used to produce glipizide lipospheres is simple, rapid, inexpensive and reproducible. The lipospheres developed employing a $3^{2}$ factorial design showed high drug encapsulation efficiency and exhibited a sustained release property for peroral use in the form of capsules. Wax loads as well as the stearic acid levels had a significant influence on the encapsulation efficiency and the drug release. The optimized formulation developed using the desirability approach produced sustained anti-diabetic activity in rats following oral administration.

Acknowledgements. - The authors are thankful to Micro Nova Laboratories Pvt. Ltd., Bangalore, for providing the gift sample of glipizide. They are grateful to Sri Prabhakar Kore, Chancellor, KLE Academy of Higher Education and Research, Deemed University, Belgaum, for providing facilities to carry out the research work.

\section{REFERENCES}

1. M. Efentakis and A. Koutlis, Release of furosemide from multiple-unit and single- unit preparations containing different viscosity grades of sodium alginate, Pharm. Dev. Tech. 6 (2001) 91-98; DOI: $10.1081 /$ PDT-100000048.

2. S. Benita, Survey of Microencapsulation Processes, in Microencapsulation: Methods and Industrial Applications, Marcel Dekker, New York 1996, pp. 1-20.

3. I. El-Gibaly and S. K. Abdel-Ghaffer, Effect of hexacosanol on the characteristics of novel sustained-release allupurinol solid lipospheres: factorial design application and product evaluation, Int. J. Pharm. 294 (2005) 33-51; DOI: 10.1016/j.ijpharm.2004.12.027.

4. J. Varrshosaz and M. Keihanfar, Development and evaluation of sustained-release propranolol wax microspheres, J. Microencaps. 18 (2001) 277-284; DOI: 10.1080/02652040010018074.

5. R. K. Verma and S. Garg, Development and evaluation of osmotically controlled oral drug delivery system of glipizide, Eur. J. Pharm. Biopharm. 57 (2004) 513-525; DOI: 10.1016/j.ejpb.2004. 02.003 . 
6. S. Jamzad and R. Fassihi, Development of controlled release low dose class II drug-glipizide, Int. J. Pharm. 312 (2006) 24-32; DOI: 10.1016/j.ijpharm.2005.12.037.

7. Martindale, The Complete Drug Reference (Ed. S. C. Sweetman), $34^{\text {th }}$ ed., Pharmaceutical Press, London 2005, pp. 324-348.

8. J. K. Patel, R. P. Patel, A. F. Amin and M. M. Patel, Formulation and evaluation of glipizide microspheres, AAPS Pharm. Sci. Tech. 6 (2005) E49-E55; DOI: 10.1208/pt 060110.

9. K. P. R. Chowdary and Y. S. Rao, Design and in vitro and in vivo evaluation of mucoadesive microcapsules of glipizide for oral controlled release, AAPS Pharm. Sci. Tech. 4 (2003) 1-6; DOI: $10.1208 /$ pt 0040339.

10. G. A. Lewis, D. Mathieu and R. Phan Tan Lui, Response Surface Methodology, in Pharmaceutical Experimental Design, Marcel Dekker, New York 1999, pp. 185-246.

11. P. J. Sinko, Micromeritics in Martin's Physical Pharmacy and Pharmaceutical Sciences (Ed. P. J. Sinko), $5^{\text {th }}$ ed., Williams \&Wilkins, Philadelphia 2006, pp. 533-560.

12. USP XXVII, NF XXII, United States Pharmacopeial Convention, Rockville 2004.

13. T. Higuchi, Mechanisms of sustained action medications: theoretical analysis of rate of release of solid drugs dispersed in solid matrices, J. Pharm. Sci. 52 (1963) 1145-1149.

14. R. W. Korsmeyer, R. Gurny, E. Doelker, P. Buri and N. A. Peppas, Mechanisms of solute release from porous hydrophilic polymers, Int. J. Pharm. 15 (1983) 25-35.

15. E. Karasulu, H. Y. Karasuslu, G. Ertan, L. Kirilmaz and T. Guneri, Extended release lipophilic indomethacin microspheres: formulation factors and mathematical equations fitted drug release rates, Eur. J. Pharm. Sci. 19 (2003) 99-104; DOI: 10.1016/S0928-0987(03)00048-4.

16. C. Narendra, M. S. Srinath and B. Prakash Rao, Development of three layered buccal compact containing metoprolol tartarate by statistical optimization technique, Int. J. Pharm. 304 (2005) 102-114; DOI: 10.1016/j.ijpharm.2005.07.021.

17. S. Jamzad and R. Fassihi, Role of surfactant and $\mathrm{pH}$ on dissolution properties of fenofibrate and glipizide - A technical note, AAPS Pharm. Sci. Tech. 7 (2006) E1-E6; DOI: 10.1208/pt 070233.

18. V. H. K. Li, V. H. L. Lee and J. R. Robinson, Influence of Drug Properties and Routes of Drug Administration on the Design of Sustained and Controlled Release Systems, in Controlled Drug Delivery (Eds. J. R. Robinson and V. H. L. Lee), $2^{\text {nd }}$ ed., Marcel Dekker, New York 1987, pp. 3-94.

19. N. Mani and H. W. Jun, Microencapsulation of a hydrophilic drug into a hydrophobic matrix using a salting-out procedure. I: Development and optimization of the process using factorial design, J. Microencapsul. 21 (2004) 125-135; DOI: 10.1080/02652040310001619776.

20. C. M. Adeyeye and J. C. Price, Development and evaluation of sustained-release ibuprofen-wax microspheres. II. In vitro dissolution studies, Pharm. Res. 11 (1994) 575-579; DOI: 10.1023/A: 1018931002991.

21. C. M. Adeyeye and J. C. Price, Development and evaluation of sustained-release ibuprofen-wax microspheres. I. Effect of formulation variables on physical characteristics, Pharm. Res. 8 (1991) 1377-1383; DOI: 10.1023/A: 1015845022112.

22. C. R. Kahn and Y. Shechter, Oral Hypoglycemic Agents and the Pharmacology of the Endocrine Pancreas, in Goodman and Gilman's The Pharmacological Basis of Therapeutics (Eds. W. R. Theodare, S. N Alan, P. Taylor and A. G. Gilman), 8 ${ }^{\text {th }}$ ed., McGraw-Hill, New York 1991, pp. 1461-1495. 
H. N. Shivakumar et al.: Design and statistical optimization of glipizide loaded lipospheres using response surface methodology, Acta Pharm. 57 (2007) 269-285.

$S A \check{Z} E T A K$

\section{Dizaj i statistička optimizacija liposfera s glipizidom pomoću metodologije odgovora površine}

HAGALAVADI NANJAPPA SHIVAKUMAR, PRAGNESH BHARAT BHAI PATEL, BAPUSAHEB GANGADHAR DESAI, PURNIMA ASHOK i SINNATHAMBI ARULMOZHI

$3^{2}$ faktorijalni dizajn je primijenjen za pripravu liposfera s glipizidom metodom separacije pomoću emulzija koristeći parafinski vosak i stearinsku kiselinu kao tvari za usporavanje. Pomoću $F$-testa praćen je učinak kritičnih varijabli tijekom formuliranja, tj. količina parafinskog voska $\left(\mathrm{X}_{1}\right)$ i udio stearinske kiseline $\left(\mathrm{X}_{2}\right)$ na srednji promjer liposfera $\left(d_{\mathrm{g}}\right)$, postotak inkapsulirane ljekovite tvari (\% $\left.E E\right)$, oslobađanje ljekovite tvari nakon $12 \mathrm{~h}\left(\mathrm{rel}_{12}\right)$ te vrijeme potrebno za oslobađanje $50 \%$ ljekovite tvari $\left(t_{50}\right)$. Za svaki parametar su pomoću multiple linearne regresijske analize (MLRA) i analize varijabli (ANOVA) načinjeni matematički modeli koji sadrže samo značajne varijable. Proučavanje varijabli na oba načina ukazalo je na njihov značajan utjecaj $(p<0,05)$ na parametre liposfera. Postavljanjem ograničenja na zavisne i nezavisne varijable provedena je numerička optimizacija na principu poželjnosti. Eksperimentalne vrijednosti $d_{\mathrm{g}} \% E E, r e l_{12}$ i $t_{50}$ optimiziranih formulacija bile su $57,54 \pm 1,38 \mu \mathrm{m}, 86,28 \pm 1,32 \%, 77,23 \pm 2,78 \%$ i 5,60 $\pm 0,32 \mathrm{~h}$. Dobivene eksperimentalne vrijednosti bile su vrlo slične vrijednostima predviđenim matematičkim modelima. Oslobađanje glipizida iz liposfera slijedio je kinetiku prvog reda i karakteriziran je Higuchijevim difuzijskim modelom. Optimizirane liposfere su nakon peroralne primjene na štakorima pokazale produljeni antidijabetički učinak.

Ključne riječi: liposfere, glipizid, faktorijalni dizajn, metodologija odgovora površine, optimizacija

Department of Pharmaceutical Technology and Department of Pharmacology, K. L. E. S's College of Pharmacy, Bangalore-560010, India 